\title{
Integrated MMI couplers based $4 \times 4$ all optical switch with absolute loss uniformity
}

\author{
Ghanshyam Singh, ${ }^{*}$ R.P.Yadav, and Vijay Janyani \\ Department of Electronics \& Communication Eng., Malaviya National Institute of Technology, Jaipur, India
}

Received October 8, 2009; accepted December 22, 2009; published December 31, 2009

\begin{abstract}
We present a compact, low-loss, completely non-blocking $4 \times 4$ optical switch possessing loss uniformity with a negligible variation of $0.8 \%-1.5 \%$. It is observed that the total switching loss ranges from $1.8 \%$ to $4.1 \%$ only with fabrication tolerances of $\pm 2.5 \%$. Integration of MMI waveguides approach has been used to optimize switching speed, losses and overall on chip area coverage of the proposed switch.
\end{abstract}

Optical computing will be an alternative to existing communication networks/technologies to overcome the issues of loss uniformity, restricted speed and power requirements. Being an essential component for all optical networks, optical switch [1] enables signals in optical fibers or integrated optical circuits (IOCs) to switch across each other. The design and fabrication of singlesubstrate-based high-order all-optical switches has been a challenging task in order to place them with other on-chip systems and applications (integrated with other devices). In integrated devices, loss uniformity [2] is an important issue which is a measure of losses that occur to all possible combinations of input and output. Switches with different losses for different input output combinations lead to an undesirable feature, i.e. an increased dynamic range of signals in the network [3]. A nonblocking $3 \times 3$ optical cross connection (OXC) with a fewer number of optical switches with uniform losses in the range of 1$3 \mathrm{~dB}$ is explained in [4]. A high order, strictly nonblocking optical cross-connect with uniformity and loss of $2.8 \mathrm{~dB}$ has been fabricated using silica-on-silicon waveguide technology with 1 x 4 MMI-based generalised Mach-Zehnder interferometers [5]. The straight MMI devices have favorable tolerance to device width, wavelength, polarization independence, and low propagation loss, particularly for ignoring bending losses, etc. [6].

MMI-based devices are much less sensitive to variations in etch depth when compared to an equivalent directional coupler, since their design does not depend significantly on etch depth [6]. The alloy GaAs/AlGaAs has been used for various high speed electronic, optoelectronic devices and their hetero structures to form multimode optical waveguides [7]. In this paper, we have designed and analyzed the performance of a non-blocking $4 \times 4$ all optical switch using integration of

*E-mail: gschoudhary75@gmail.com
$\mathrm{GaAs} / \mathrm{Al}_{\mathrm{x}} \mathrm{Ga}_{1-\mathrm{x}} \mathrm{As}$ based MMI waveguides approach in order to optimize its coverage area while maintaining loss uniformity. The dimensions of the basic switching element design were kept minimum in order to optimize interconnect losses and overall on-chip area coverage. It is obvious that for each elementary switch with small dimensions, the propagation speed will be higher and thus the switching response of the switch - better.

An all-optical switch has two inputs and two outputs, with two switching states (Figure 1): one is the "straight" state, also referred to as bar state and the other is "swap" state also referred to as cross state. The inputs and outputs are in an optical form and the switching is performed in an optical domain internally.

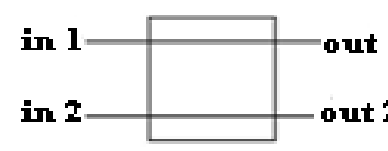

(a)

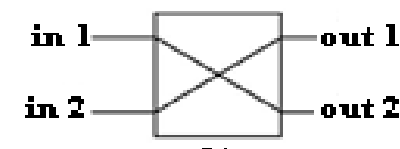

(b)
Fig. 1. Basic $2 \times 2$ switch with switching states (a) the "bar" state; (b) the "cross" state

The choice of material, switching technology, and architecture have great impact on the performance of MMI based all optical switches. Fan Wang et al [8] reported that, in MMI couplers, the field profile at the input is replicated at regular intervals and produces single and multiple mirror images, which in turn have been used for switching and power division. But this leads to high crosstalk and a less reliable system. Alternatively, by making a small change in the refractive index along the coupling length, switching can be achieved. This is known as a multi-region refractive index modulation method. Partial index-modulation regions can operate by current injection for a refractive index change and a highspeed optical switch is expected [9]. In recent years, MMI based low loss, low crosstalk, scalable and low cost switches have been developed by means of electro-optics, and thermo optics [10].

Varying the refractive index of the MMI section by a very small value - either by current injection [11] or by heating electrode [8], switching can be achieved in a MMI based optical switch. The basic structure of a $2 \times 2$ MMI optical switch with the dimensions of various 
sections, depicted in Figure 3, has been designed as follows.

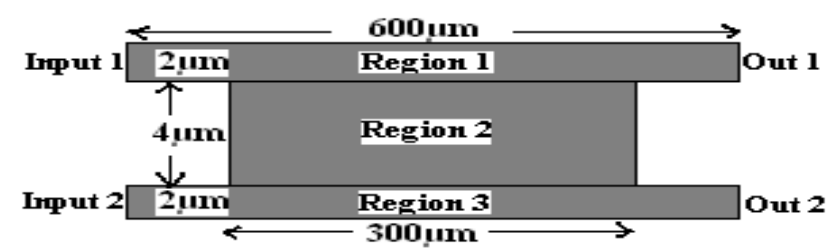

Fig. 2. Layout (not to scale) of a straight MMI coupler based $2 \times 2$ optical switch.

The structure mainly consists of three regions labeled as Region-1, Region-2, and Region-3, with refractive indices $n_{1}, n_{2}$ and $n_{3}$, respectively. The outer edges of both the input and output waveguides coincide with the edges of the MMI region. To work with the switch in the BAR state, we have set $n_{1}=n_{3}=n_{0}$ and $n_{2}=n$, such that $n_{0}>n$. In order to achieve output in the CROSS state, we have set $\mathrm{n}_{1}=\mathrm{n}_{2}=\mathrm{n}_{3}=\mathrm{n}_{0}$. The value of fraction $\mathrm{x}$ for waveguide material $\mathrm{Al}_{\mathrm{x}} \mathrm{Ga}_{1-\mathrm{x}} \mathrm{As}$ has been varied (from 0.9 to 0.5 ) to change the refractive index of the coupling region ' 2 ' $\left(\mathrm{n}_{2}\right)$ : from 3.058 to 3.15 by the current injection method. Wavelength influence (in the range of $800-900 \mathrm{~nm}$ ) on $\mathrm{Al}_{\mathrm{x}} \mathrm{Ga}_{1-\mathrm{x}}$ As refractive index has been taken into account by changing $\mathrm{x}$ with heating current $(10 \mathrm{~mA})$. Passive simulations confirm that the design can exhibit overall loss of $0.3 \mathrm{~dB}$ with crosstalk lower than $20 \mathrm{~dB}$. The designed switch has been used as a switching element (SE) for realization of the proposed $4 \times 4$ switch.

The proposed $4 \times 4$ optical switch has been designed by integrating six $2 \times 2$ switches on a single substrate. The switching element's connection is chosen in order to have a smaller number of switching elements and reduced physical area. The total device size has been reduced to $0.20 \mathrm{~mm}$ (width) x $2.8 \mathrm{~mm}$ (length) less than reported in [10] [12], being also compatible with on chip applications. We have used optical signals of frequency 193.2 THz with different power level 10, 20, 30 and 40 $\mathrm{mW}$. The fabrication tolerances of $\pm 2.5 \%$ (for length \& width dimension of the device) were achieved by optimizing the output/input channel separation of internal SE's. We have used these power levels with different connection patterns [5] to check its loss uniformity and non blocking switching nature [10] [13] for all possible input/output patterns. Uniformity is the difference between the maximum and minimum output powers at output ports [14]. Figure 3 depicts a 3 layered cross sectional view of the proposed $4 \times 4$ switch with a substrate, MMI sections and electrode regions. The electrode regions have been developed across the individual SEs in order to alter the refractive indices so as to perform the switching in them. A finite difference beam propagating method was used to investigate lightwave propagation in axially varying waveguides. Design and 2D isotropic simulation results were produced using an OPTIBPM analyzer and simulator with VB scripting. Perfectly matched layer (PML) boundary conditions were used, which defines the truncation of the computation domain by layers without any reflection irrespective of signal frequencies [15]. To check switch loss uniformity, input signals of different power levels covering 24 possible combinations randomly were used. Table I shows all possible output w.r.t inputs 1,2,3,4 with corresponding states (bar and cross states) for individual SEs.

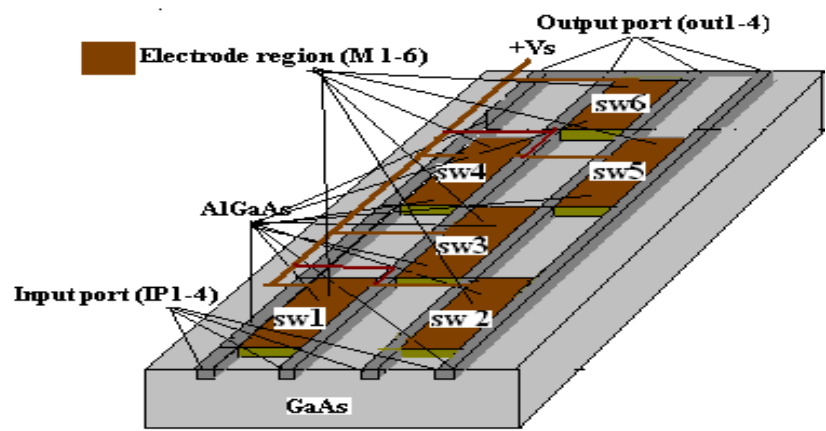

Fig. 3. View (cross sectional and top) of the proposed $4 \times 4$ switch (IP denotes input port, Out denotes output port and SW denotes a switch, M: $1-6$, electrode region)

TABLE- I: States of different switches ( $\mathrm{B}=\mathrm{Bar}, \mathrm{C}=\mathrm{Cross})$

\begin{tabular}{|c|c|c|c|c|c|c|c|c|c|}
\hline \multicolumn{3}{|c|}{ Output pattern } & \multicolumn{6}{|c|}{ States of different switches } \\
\hline $\mathrm{a}$ & $\mathrm{b}$ & $\mathrm{c}$ & $\mathrm{d}$ & $\mathrm{S} 1$ & $\mathrm{~S} 2$ & $\mathrm{~S} 3$ & $\mathrm{~S} 4$ & $\mathrm{~S} 5$ & $\mathrm{~S} 6$ \\
\hline 1 & 2 & 3 & 4 & $\mathrm{~B}$ & $\mathrm{~B}$ & $\mathrm{~B}$ & $\mathrm{~B}$ & $\mathrm{~B}$ & $\mathrm{~B}$ \\
\hline 1 & 2 & 4 & 3 & $\mathrm{~B}$ & $\mathrm{C}$ & $\mathrm{B}$ & $\mathrm{B}$ & $\mathrm{B}$ & $\mathrm{B}$ \\
\hline 1 & 3 & 2 & 4 & $\mathrm{~B}$ & $\mathrm{~B}$ & $\mathrm{C}$ & $\mathrm{B}$ & $\mathrm{B}$ & $\mathrm{B}$ \\
\hline 1 & 3 & 4 & 2 & $\mathrm{~B}$ & $\mathrm{~B}$ & $\mathrm{C}$ & $\mathrm{B}$ & $\mathrm{C}$ & $\mathrm{B}$ \\
\hline 1 & 4 & 2 & 3 & $\mathrm{~B}$ & $\mathrm{C}$ & $\mathrm{C}$ & $\mathrm{B}$ & $\mathrm{B}$ & $\mathrm{B}$ \\
\hline 2 & 4 & 3 & 2 & $\mathrm{~B}$ & $\mathrm{C}$ & $\mathrm{C}$ & $\mathrm{B}$ & $\mathrm{C}$ & $\mathrm{B}$ \\
\hline 2 & 1 & 3 & 4 & $\mathrm{C}$ & $\mathrm{B}$ & $\mathrm{B}$ & $\mathrm{B}$ & $\mathrm{B}$ & $\mathrm{B}$ \\
\hline 2 & 3 & 4 & 3 & $\mathrm{C}$ & $\mathrm{C}$ & $\mathrm{B}$ & $\mathrm{B}$ & $\mathrm{B}$ & $\mathrm{B}$ \\
\hline 2 & 3 & 4 & 1 & $\mathrm{C}$ & $\mathrm{B}$ & $\mathrm{C}$ & $\mathrm{B}$ & $\mathrm{C}$ & $\mathrm{B}$ \\
\hline 2 & 4 & 1 & 3 & $\mathrm{C}$ & $\mathrm{C}$ & $\mathrm{C}$ & $\mathrm{B}$ & $\mathrm{B}$ & $\mathrm{B}$ \\
\hline 2 & 4 & 3 & 1 & $\mathrm{C}$ & $\mathrm{C}$ & $\mathrm{C}$ & $\mathrm{B}$ & $\mathrm{C}$ & $\mathrm{B}$ \\
\hline 3 & 1 & 2 & 4 & $\mathrm{~B}$ & $\mathrm{~B}$ & $\mathrm{C}$ & $\mathrm{C}$ & $\mathrm{B}$ & $\mathrm{B}$ \\
\hline 3 & 1 & 4 & 2 & $\mathrm{~B}$ & $\mathrm{~B}$ & $\mathrm{C}$ & $\mathrm{C}$ & $\mathrm{C}$ & $\mathrm{B}$ \\
\hline 3 & 2 & 1 & 4 & $\mathrm{~B}$ & $\mathrm{~B}$ & $\mathrm{C}$ & $\mathrm{C}$ & $\mathrm{B}$ & $\mathrm{C}$ \\
\hline 3 & 2 & 4 & 1 & $\mathrm{C}$ & $\mathrm{B}$ & $\mathrm{C}$ & $\mathrm{C}$ & $\mathrm{C}$ & $\mathrm{B}$ \\
\hline 3 & 4 & 1 & 2 & $\mathrm{~B}$ & $\mathrm{~B}$ & $\mathrm{C}$ & $\mathrm{C}$ & $\mathrm{C}$ & $\mathrm{C}$ \\
\hline 3 & 4 & 2 & 1 & $\mathrm{C}$ & $\mathrm{B}$ & $\mathrm{C}$ & $\mathrm{C}$ & $\mathrm{C}$ & $\mathrm{C}$ \\
\hline 4 & 1 & 2 & 3 & $\mathrm{~B}$ & $\mathrm{C}$ & $\mathrm{C}$ & $\mathrm{C}$ & $\mathrm{B}$ & $\mathrm{B}$ \\
\hline 4 & 1 & 3 & 2 & $\mathrm{~B}$ & $\mathrm{C}$ & $\mathrm{C}$ & $\mathrm{C}$ & $\mathrm{C}$ & $\mathrm{B}$ \\
\hline 4 & 2 & 1 & 3 & $\mathrm{C}$ & $\mathrm{C}$ & $\mathrm{C}$ & $\mathrm{C}$ & $\mathrm{B}$ & $\mathrm{B}$ \\
\hline 4 & 2 & 3 & 1 & $\mathrm{C}$ & $\mathrm{C}$ & $\mathrm{C}$ & $\mathrm{C}$ & $\mathrm{C}$ & $\mathrm{B}$ \\
\hline 4 & 3 & 1 & 2 & $\mathrm{~B}$ & $\mathrm{C}$ & $\mathrm{C}$ & $\mathrm{C}$ & $\mathrm{C}$ & $\mathrm{C}$ \\
\hline 4 & 3 & 2 & 1 & $\mathrm{C}$ & $\mathrm{C}$ & $\mathrm{C}$ & $\mathrm{C}$ & $\mathrm{C}$ & $\mathrm{C}$ \\
\hline
\end{tabular}

Figure 4 presents a visual of switching occurring internally for optical powers applied to specific input/output patterns. Similarly, other combinations were also realized and the device was found completely nonblocking. 


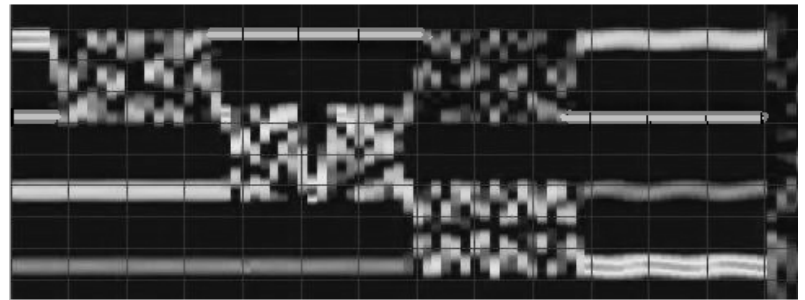

Fig. 4. 2D view of internal switching effects for one possible input/output combination $\left(\mathrm{s}_{1}, \mathrm{~s}_{3}, \mathrm{~s}_{4}, \mathrm{~s}_{5}\right.$ are in cross states and $\mathrm{s}_{2}, \mathrm{~s}_{6}$ are in bar states).

The power levels at subsequent output ports were measured for two different refractive indexed modulated regions, i.e. for $n_{2}=3.058$ and 3.15 . The average loss was calculated for each input and output pattern and results were then plotted using MATLAB 7.0 to check the variations in switching losses for every possible input/output combination. As shown in Figure 5, it is observed that with $\mathrm{n}_{2}=3.058$, the switch possesses loss uniformity with a variation of $0.5 \%$ and average loss of $1.8 \%$ only. For $\mathrm{n}_{2}=3.15$, loss uniformity with a variation of $1.5 \%$ and average loss of $4.1 \%$ were observed. Two different refractive indexed MMI regions with $\mathrm{n}_{2}=3.15$ and 3.058 were considered in order to follow the principle of parallelism [16], which also verifies the uniform switching characteristic for both cases. Therefore, the integration of an uniformly structured MMI waveguides approach resulted in reduced on chip area with enhanced loss uniformity as compared to [4] [5] [14].

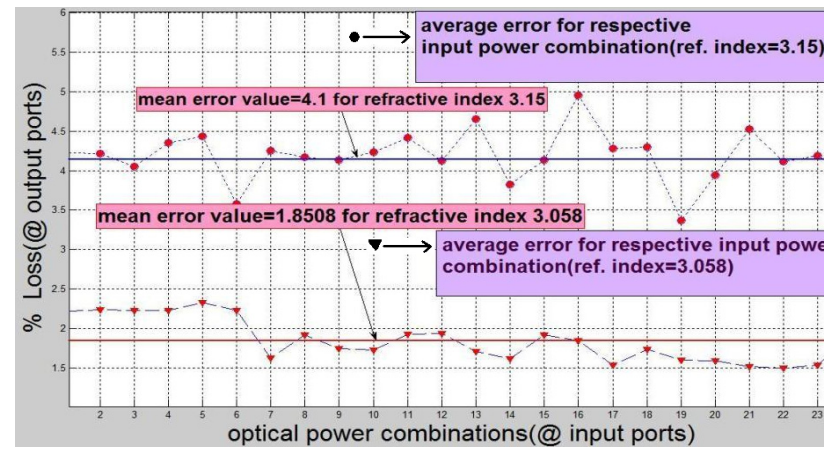

Fig.5. \% Loss (@output ports) for all possible power patterns (@ input ports), showing loss uniformity variation of $0.8 \%-1.5 \%$ with tota switching loss between $1.8 \%-4.1 \%$ only with $\mathrm{n}_{2}=3.15 \& 3.058$

In summary, we report a compact, low loss, completely non-blocking $4 \times 4$ integrated MMI all optical switch with absolute loss uniformity. The reductions in elementary switch lead to lower power consumption and physical device area. The architecture is extendable into $8 \times 8$ and $16 \times 16$ switching matrices. Loss uniformity is an important aspect to be considered thoroughly before fabricating integrated all-optical switches for system on chip applications. Integrated MMI sections need to be fabricated carefully to avoid overlapping errors and to make the best use of on-chip area coverage.

The work is dedicated to the Institutional excellence in optics research under the grants available from project TEQIP, Ministry of Human Resources Development, Government of India, for the procurement of an optiwave simulator.

\section{References}

[1] G.I. Papadimitriou, Ch. Papazoglou, and A.S. Pomportsis (2003) "Optical Switching: Switch Fabrics, Techniques, and Architectures" J. Lightwave Technol. 21, 384-405 (2003).

[2] R. Yin, J. Yang, X. Jiang, J. Li, and M. Wang "Improved approach to low-loss and high-uniformity MMI devices" Opt. Commun. 181, 317-321 (2000).

[3] R. Ramaswami, K.N. Sivarajan, Optical networks: A practical perspective, 2nd Edition, Morgan Kaufmann, 2002.

[4] Z. Tao, J. Chen, D. Wu, A. Xu, "Nonblocking 3x3 OXC with less optical switches" Fifth Asia-Pacific Conference on Communications and Fourth Optoelectronics and Communications Conference, 1999. APCC/OECC '99. Vol. 1, 18-22 Oct. 1999 page(s):454 - 455, 1999.

[5] M.P. Earnshaw, J.B.D. Soole, M. Cappuzzo, L. Gomez, E. Laskowski, A. Paunescu "Compact, low-loss 4 x 4 optical switch matrix using multimode interferometers", Electron. Lett. 37, 115116 (2001).

[6] D.S. Levy, Y. M. Li, R. Scarmozzino, and R.M. Osgood, "A Multimode Interference-Based Variable Power Splitter in GaAsAlGaAs" IEEE Photonics Tech. Lett. 9, 1373-1375 (1997).

[7] S.R. Kisting et al "High precision temperature- and energydependent refractive index of GaAs determined from excitation of optical waveguide eigenmodes”, Appl. Phys. Lett. 57, 1328 (1990).

[8] F. Wang, J. Yang, L. Chen, X. Jiang, and M. Wang, "Optical switch based on multimode interference coupler", IEEE Photonics Technol. Lett. 18, (2006).

[9] S. Kumai, T. Ishikawa, A. Okazaki, K. Utaka, H. Amanai, K. Kurihara, and K. Shimoyama, "High-speed optical switching of InAlGaAs/InAlAs multi-mode interference photonic switch with partial index-modulation region (MIPS-P)", IEICE Electron. Express 2, 578-582 (2005).

$[10]$ N. Xie and K. Utaka, "Proposal of a Novel MMI-Based NxN NonBlocking Optical Ring Switch", Optical Fiber Communication and the National Fiber Optic Engineers Conference, OFC/NFOEC, page: 1 - 3, 25-29 March 2007.

[11]S. S. Agashe, K.-T. Shiu, and S. R. Forrest "Compact polarizationinsensitive InGaAsP-InP 2x 2 optical switch" IEEE Photonics Technol. Lett. 17, (2005).

[12] Ch. Shaowu; Y. Jinzhong; L. Jingwei; W. Zhangtao; X. Jinsong, "First IEEE International Conference on Group IV Photonics, 29 Sept.-1 Oct. 2004 Page(s):46 - 48, 2004.

[13] Y..Jinzhong et al. "Research progresses of SOI optical waveguide devices and integrated optical switch matrix" Science in China Press, co-published with Springer-Verlag GmbH, page no. 234-246, Vol. 48, No.2, April, 2005.

[14]Z. Jin and G. Peng, "Designing optical switches based on silica multimode interference devices" Progress in Electromagnetic Research Symposium 2005, Hangzhou, China, August 22-26, page no. 58-61, 2005.

[15] OptiBPM "Technical background and tutorials" waveguide optics modeling software system, Version 8.0, second edition, Optiwave Inc. 2006.

[16]M. Maier, “Optical switching networks", University of Québec, Montréal, Cambridge publications, ISBN-13: 9780521868006, 2008 . 